\title{
The measles outbreak in Bulgaria, 2009-2011: An epidemiological assessment and lessons learnt
}

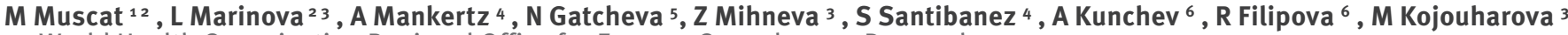

1. World Health Organization Regional Office for Europe, Copenhagen, Denmark

2. Both authors contributed equally as first authors.

3. National Centre of Infectious and Parasitic Diseases, Sofia, Bulgaria

4. Robert Koch Institute, WHO/EURO Regional Reference Laboratory for Measles and Rubella, Berlin, Germany

5. Bulgarian Association for Prevention and Infection Control - BulNoso, Sofia, Bulgaria

6. Ministry of Health, Sofia, Bulgaria

Correspondence: Mark Muscat (mms@euro.who.int)

Muscat M, Marinova L, Mankertz A, Gatcheva N, Mihneva Z, Santibanez S, Kunchev A, Filipova R, Kojouharova M. The measles outbreak in Bulgaria, 2009-2011: An epidemiological assessment and lessons learnt. Euro Surveill. 2016;21(9):pii=30152. DOI: http://dx.doi.org/10.2807/1560-7917.ES.2016.21.9.30152

Measles re-emerged in a nationwide outbreak in Bulgaria from 2009 to 2011 despite reported high vaccination coverage at national level. This followed an eight-year period since the last indigenous cases of measles were detected. The Bulgarian National Centre of Infectious and Parasitic Diseases collated measles surveillance data for 2009-2011. We analysed data for age group, sex, ethnicity, diagnosis confirmation, vaccination, hospitalisation, disease complications, and death and describe the outbreak control measures taken. The outbreak started in April 2009 following an importation of measles virus and affected 24,364 persons, predominantly Roma. Most cases (73\%) were among children $<15$ years old. Vaccination status was available for $52 \%(n=12,630)$ of cases. Of children 1-14 years old, $22 \%(n=1,769)$ were unvaccinated and $70 \%(n=5,518)$ had received one dose of a measles-containing vaccine. Twenty-four measles-related deaths were reported. The Roma ethnic group was particularly susceptible to measles. The magnitude of the outbreak resulted primarily from the accumulation of susceptible children over time. This outbreak serves as a reminder that both high vaccination coverage and closing of immunity gaps across all sections of the population are crucial to reach the goal of measles elimination.

\section{Introduction}

One of the largest outbreaks of measles in the World Health Organization (WHO) European Region in recent years occurred in Bulgaria from 2009 to 2011 and mostly affected Roma communities. The outbreak was first detected in spring 2009 after an eight-year period since the last indigenous measles cases were reported in 2001 [1]. The last major outbreak in Bulgaria occurred in 1991-1992 affecting over 20,000 persons [2].
By December 2009, two preliminary reports on the outbreak were published in the scientific literature $[3,4]$. Here we provide an overview of the measles outbreak in Bulgaria by analysing measles surveillance data for the whole outbreak period of 2009-2011. We also describe the control measures taken and discuss lessons learnt in relation to the WHO European Regional goal of eliminating measles by 2015 [5].

The measles vaccine was introduced in Bulgaria in 1969 as a monovalent preparation [6]. A two-dose schedule began in 1983. The combined measles-mumps-rubella (MMR) vaccine has been given as the first dose at 13 months of age since 1993, and as the second dose at 12 years of age since 2001. For 2003-2008, the estimated national vaccine administrative coverage with the first MMR vaccine dose ranged from $94.7 \%$ to $96.2 \%$, and for the second dose, from $89.4 \%$ to $94.3 \%$ [7].

Bulgaria forms part of the Balkan Peninsula in southeastern Europe and consists of 28 administrative regions. The latest census carried out in 2011 reported a population of $7,364,570$, consisting of three main ethnic groups: Bulgarians (84.8\%), Turks (8.8\%) and Roma (4.9\%). According to these official statistics, the Roma ethnic group numbers 325,343 persons distributed in all regions, but mainly in Montana $(12.7 \%$ of population), Sliven (11.8\%), Dobrich (8.8\%) and Yambol (8.5\%) [8].

\section{Methods}

Epidemiological data

The surveillance of measles in Bulgaria relies on passively reported cases. Measles has been a statutory notifiable disease since 1921 [9], and medical practitioners and medical laboratories are obliged to 
Number of reported measles cases by month of onset of rash, Bulgaria, 2009-2011 ( $\mathrm{n}=24,364)$

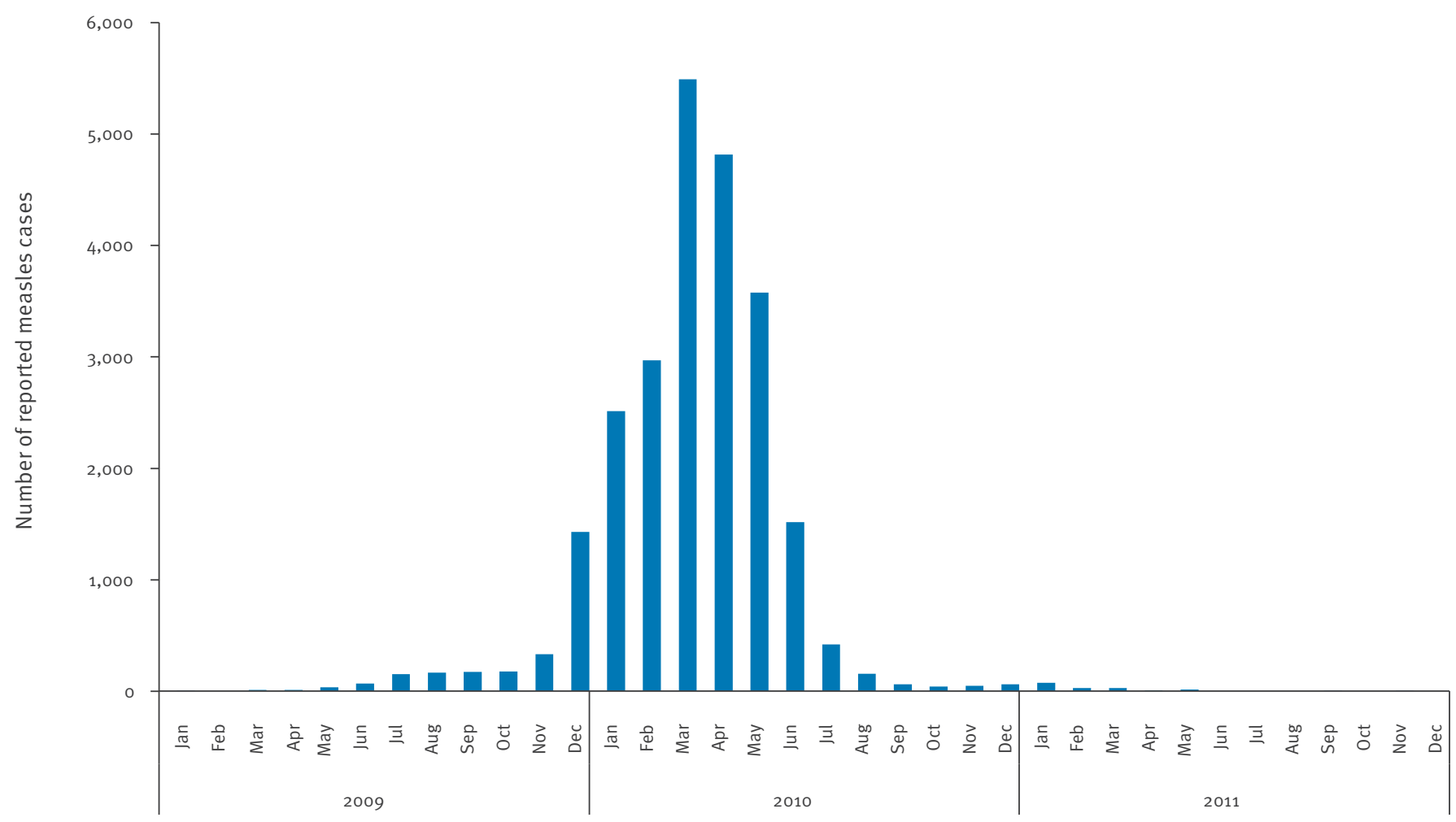

Month of onset of rash

immediately report suspected measles cases to the respective Regional Health Inspectorate (RHI) [10]. The RHIs are responsible for the epidemiological investigation of cases, tracing contacts of cases, undertaking control measures in affected families and communities and following up cases to register disease outcome. In 2005, the European Union case definition and case classification were adopted for reporting measles surveillance data [11].

During the outbreak period 2009-2011, case-based data were submitted by all 28 RHIs to the Department of Epidemiology and Communicable Disease Surveillance of the National Centre of Infectious and Parasitic Diseases (NCIPD) in Sofia. In October 2009, a webbased system for direct case-based data entry by the RHIs was implemented, gradually replacing previous manual methods of data collection and submission.

Case-based reports provided data for disease onset dates, date of birth, sex, diagnosis confirmation (i.e. laboratory-confirmed, epidemiologically linked and clinically compatible cases), vaccination, hospitalisation, complications and death. Information on vaccination status was obtained from patient immunisation cards whenever such cards were available. The investigators of the outbreak estimated the number of cases in Roma in parallel to routine data collection. We analysed surveillance data of cases with disease onset from 2009 until 2011 and separated the data by specified age groups.

\section{Laboratory data}

Laboratory confirmation of cases was carried out by detecting measles IgM antibodies in serum samples submitted mainly to the National Reference Laboratory of the NCIPD and, to a lesser extent, to the laboratories of three regional military hospitals. Clinical specimens of 20 laboratory-confirmed cases were submitted to the WHO European Regional Reference Laboratory for Measles and Rubella at the Robert Koch Institute in Berlin, Germany to determine the genotype of the measles virus (MV) circulating during the outbreak and to identify the likely origin of the virus. The specimens were taken from case-patients in different regions at various points in time (April 2009, May 2009, January 2010, June 2010 and January 2011). Serum was sent for confirmatory testing, and urine specimens and throat swabs were submitted for virus detection, sequencing and genotyping of the MV RNA following standard instructions [12]. IgM and IgG serology tests were carried out as described by Tischer et al. [13] and genotyping was performed according to the WHO recommendation [14]. Sequences were aligned using ClustalW [15] and further analysed using SeqScape 2.5 and MEGA 4.0 DNA analysis software [16]. Phylogenetic trees were constructed using the neighbour-joining method. Genotype assignment was performed by 


\section{FIGURE 2}

Incidence of measles cases by region in Bulgaria, 2009-2011

A. 2009 (33.6/100,000 population)

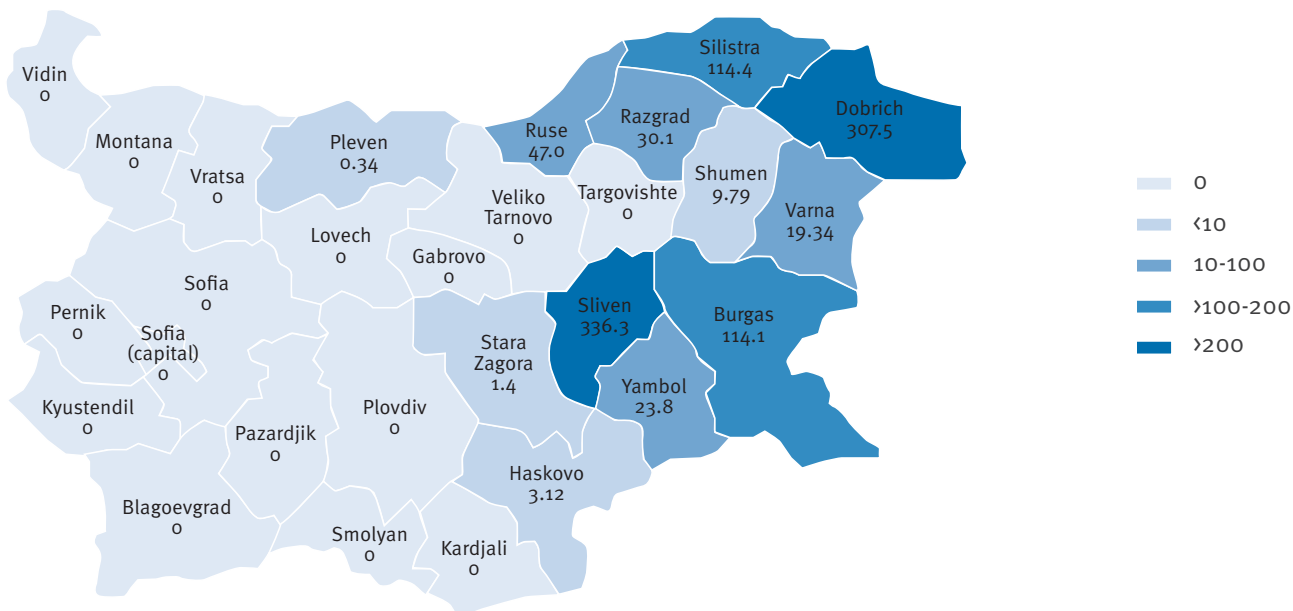

B. $2010(288.7 / 100,000$ population $)$

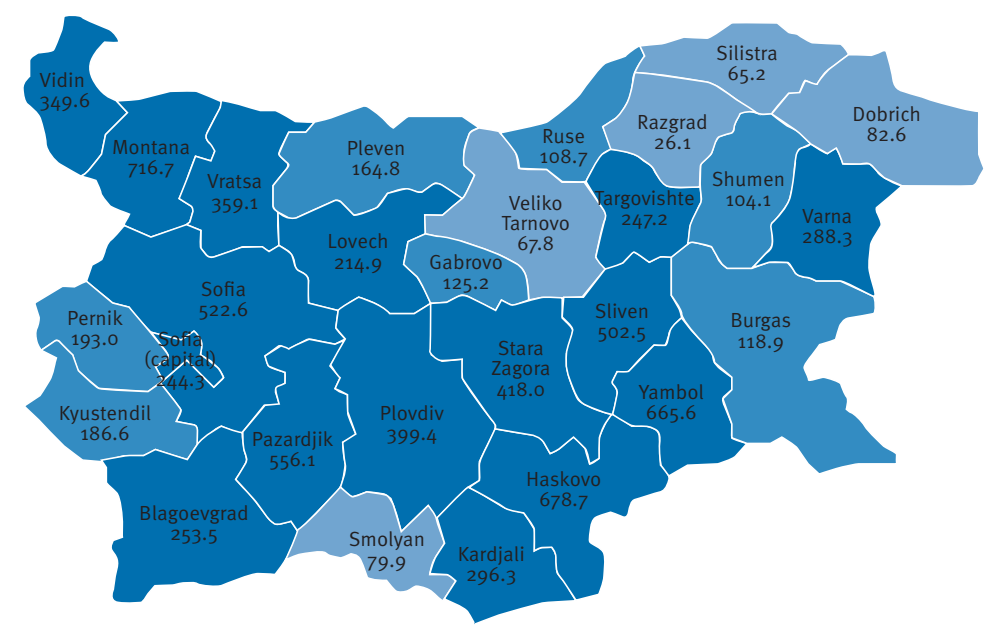

0

- $<10$

10-100

$>100-200$

- $>200$

\section{2011 (2.1/100,000 population)}

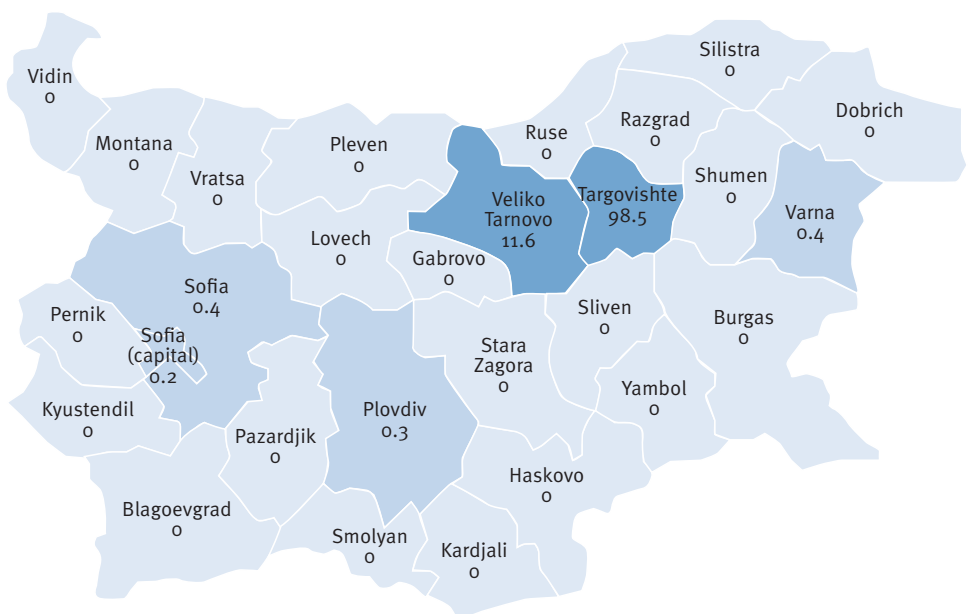




\section{FIGURE 3}

Phylogenetic relationship between the World Health Organization reference strain of measles virus genotype D4 (MVs/Montreal.CAN/89-Ref-[D4]) and MV strains detected in measles outbreak in Bulgaria, 2009-2011

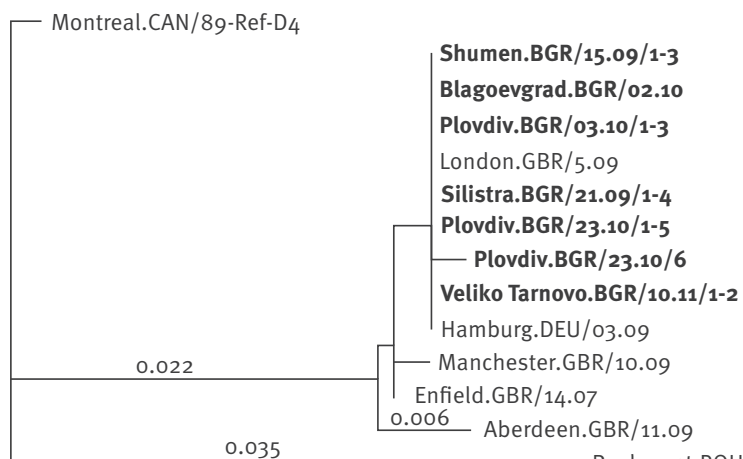
Bucharest.ROU/48.04/1

$\stackrel{0.005}{1}$

Measles virus (MV) strains detected in Bulgaria are shown in bold. The World Health Organization-named strains of MV genotype D4 (MVs/Enfield.GBR/14.07, MVs/Manchester.GBR/10.09 and MVs/Hamburg.DEU/03.09) circulating in Europe in the same period are also included. The unrooted tree is based on the 456 nt sequence encoding the C-terminus of the MV N gene. The phylogenetic distance scale bar indicates estimated changes per nucleotide.

phylogenetic comparison with the MV reference strains as designated by WHO [17]. The obtained sequence data, genotype information and the official WHO MV sequence name and relevant epidemiologic data were submitted to the WHO database, Measles Nucleotide Surveillance (MeaNS) database [18] and GenBank.

\section{Incidence and case-fatality calculations}

Incidence was calculated with the number of measles cases as the numerator and the country and region population, obtained from the National Statistical Institute, as the denominator [19]. Unless otherwise specified, we expressed incidence per 100,000 inhabitants per year, and cumulatively for the threeyear period 2009-2011. Case-fatality ratio (CFR) was expressed as the number of measles-related deaths per 100 cases for the three-year period 2009-2011.

Ethical approval or informed consent was not considered to be necessary for this analysis since the data were collated under the Ministry of Health's Regulation 21 on epidemiological surveillance and control of communicable diseases in Bulgaria [10].

\section{Results}

Overall, 24,364 cases of measles were recorded between April 2009 and December 2011 corresponding to a cumulative incidence of 326 per 100,000 inhabitants over the three-year period. The outbreak reached its peak by March 2010 (monthly incidence: 73 per 100,000 inhabitants) when all 28 regions of Bulgaria were affected (Figure 1). Figure 2 shows the incidence of measles by region and by year, 2009-2011. During the three-year period of the outbreak, the highest incidence ( $>500$ cases/100,000 inhabitants) was registered in the regions of Sliven (838.8/100,000 inhabitants), Montana (716.7), Yambol (689.5), Haskovo (681.8), Pazardjik (556.1) and the Sofia region (523.0).

Of the total, 3,958 cases (16\%) were laboratory-confirmed by detecting measles IgM antibodies in serum samples, 8,233 (34\%) cases were epidemiologically linked to a laboratory-confirmed case and 12,173 (50\%) cases were classified as clinically compatible cases.

Of the total, 12,472 (51\%) were males. The median age of the cases was seven years (range: one day to 71 years). Infants had the highest age-specific incidence per 100,000 inhabitants of 5,457 followed by 2,008 in children aged one to four years. Table 1 shows the age distribution of cases. Data on vaccination status were available for $52 \%(n=12,630)$ of all reported cases (Table 2). Of the cases vaccinated with one MMR vaccine dose $(n=6,167 ; 49 \%), 11 \%(n=656)$ were vaccinated within 14 days before onset of disease.

Of the total, $21,821(89.6 \%)$ cases were estimated to occur among Roma. Indeed, the outbreak was first detected in April 2009 among the Roma community in the north-eastern part of the country involving the regions of Razgrad, Shumen, Silistra and Dobrich. The index case was identified as member of the Roma community aged between 20 and 30 years, who fell ill in March 2009, a few days after returning home from Hamburg, Germany. Initial symptoms included high fever, cough, coryza and malaise followed by the development of a rash three days later. The clinical suspicion of measles was confirmed by serological tests. Three of the index case's family members subsequently acquired laboratory-confirmed measles. At the outset, the detection of further cases was delayed.

\section{Mortality, hospitalisation and complications}

Measles-related deaths were recorded in 24 patients (14 laboratory-confirmed, five epidemiologically linked, and five clinical cases), corresponding to a CFR of 0.1 per 100 measles cases. The deaths occurred as a consequence of severe complications of measles: 19 cases (79\%) suffered acute pneumonia and five cases (21\%) suffered acute encephalitis. The median age at death was 1.71 years (range: 32 days -54 years). Infants and cases aged $\geq 25$ years had a higher CFR (0.28\% and $0.2 \%$, respectively) compared with cases aged 1-24 years $(0-0.09 \%)$. All deaths, with the exception of two cases of Bulgarian ethnicity aged between 40 and 49 years of age, occurred in Roma.

Data on hospitalisation status were available for $92 \%$ $(n=22,296)$ of cases, of whom $86 \%(19,167)$ were hospitalised. Among those hospitalised, 88\% (16,854) were aged<19 years. Information on measles-related complications was reported in $86 \%(21,039)$ of cases, of whom $38 \%(8,074)$ reported complications (Table 3$)$. 
TABLE 1

Age distribution of measles cases $(n=24,364)$ and measles-related deaths $(\mathrm{n}=24)$, Bulgaria, 2009-2011

\begin{tabular}{|l|c|c|c|}
\hline Age group (years) & $\begin{array}{c}\text { No. of cases } \\
(\mathrm{n}=24,364) \\
(\% \text { of total reported } \\
\text { cases) }\end{array}$ & $\begin{array}{c}\text { Deaths } \\
(\mathrm{n}=24)\end{array}$ & $\begin{array}{c}\text { Case-fatality } \\
\text { ratio \% }\end{array}$ \\
\hline$<1$ & $3,891(16)$ & 11 & 0.28 \\
\hline $1-4$ & $5,858(24)$ & 5 & 0.09 \\
\hline $5-9$ & $3,473(14)$ & 2 & 0.06 \\
\hline $10-14$ & $4,706(19)$ & 1 & 0.02 \\
\hline $15-19$ & $3,167(13)$ & 1 & 0.03 \\
\hline $20-24$ & $1,246(5)$ & 0 & 0 \\
\hline$\geq 25$ & $2,023(8)$ & 4 & 0.20 \\
\hline
\end{tabular}

\section{Molecular typing}

All three nucleotide (nt) sequences of the variable part of MV N-gene (456 nt) derived from the three household contacts of the index case (MVs/Shumen. $\mathrm{BGR} / 15.09 / 1-3$ [D4]) were identical to D4-Hamburg (MVs/Hamburg.DEU/03.09). D4-Hamburg showed a sequence deviation of one nt from D4-Enfield (MVs/ Enfield.GBR/14.07/[D4]), which was endemic in the United Kingdom between 2007 and 2009 [20,21].

The sequences derived from samples collected from four further cases later in 2009 are represented by MVs/Silistra.BGR/21.09/1-4 [D4]. In 2010, specimens from different parts of the country were collected and evaluated: from south-western (MVs/Blagoevgrad. BGR/02.10/1 [D4], central (MVs/Plovdiv.BGR/03.10/1-6 [D4] and northern Bulgaria (MVs/VelikoTarnovo. BGR/10.11/1-2 [D4]). Nineteen out of the 20 laboratoryconfirmed cases that submitted clinical specimens for further laboratory analysis showed the sequence variant D4-Hamburg (Figure 3). MVs/Plovdiv.BGR/23.10/6 [D4] was characterised by a sequence deviation of one nt, probably as a result of mutation.

\section{Outbreak control measures}

\section{Outbreak management}

The local health authorities implemented several control measures in line with the Bulgarian National Programme for the Elimination of Measles and Congenital Rubella Infection (2005-2010) [22]. The same month the outbreak was detected persons of Roma ethnicity living in the first-affected north-eastern regions of the country aged between 13 months and 30 years were targeted for immunisation with one dose of MMR vaccine. In February 2010, the campaign was extended to a national level targeting persons aged 13 months to 20 years who had not received two MMR vaccine doses. From the end of March 2010, the vaccine was available on request to all persons aged 30 years and older who had not received two MMR vaccine doses. Throughout the outbreak period, healthcare workers were offered a dose of MMR vaccine, irrespective of their immunisation status or age. Between April 2009 and December 2010, 188,700 MMR vaccine doses were administered free of charge by the Ministry of Health $(\mathrm{MoH})$ through routine immunisation services.

Special outreach teams composed of local epidemiologists and health inspectors in collaboration with Roma health mediators (RHM) were deployed to vaccinate Roma communities. RHM are usually young adult members of the Roma community who are specially educated in the health field and trained to liaise between the community and healthcare facilities [23]. RHM assisted vaccination teams by improving communication between the team members, and leaders and members of the Roma community; by informing Roma leaders and parents of the benefits of vaccinations and by facilitating the transport of children to immunisation centres.

The $\mathrm{MoH}$ recommended that patients with measles living in crowded households be admitted to hospital to ensure better conditions for treatment and care and to minimise the spread of the disease in the poor neighbourhoods.

Outbreak communication

Activities to increase awareness of the outbreak among the public and healthcare professionals were undertaken. When the outbreak started spreading beyond the north-eastern part of Bulgaria, the $\mathrm{MoH}$ issued a press release on the emerging outbreak, and provided information on the surveillance and immunisation activities. The $\mathrm{MoH}$ website also provided regularly updated information. Information leaflets were also distributed to the general population, and specifically to Roma, via their religious and community leaders. Information packages including a description of measles, updates on the status of the outbreak and a call to the public to be vaccinated were also regularly supplied to the media.

The MoH distributed official circular letters to medical professionals in April 2009, August 2009 and February 2010. Medical professionals were requested to pay special attention to patients presenting with rash and fever, to reach out to parents to explain the benefits of vaccination, and to ensure timely routine MMR vaccination of children.

\section{Additional measures}

The MoH regularly informed the WHO Regional Office for Europe and the European Centre for Disease Prevention and Control (ECDC) on the outbreak situation and measures taken to mitigate it. In February 2010, experts from both organisations worked closely with the Bulgarian public health authorities to assess the outbreak and potential risk for further spread beyond the country, to review the current vaccination strategies and MMR vaccine supplies in the country for efficient control measures and to provide guidance on long-term strategies that address vaccination among 
Measles cases with known vaccination status, Bulgaria, 2009-2011 ( $\mathrm{n}=12,630)$

\begin{tabular}{|c|c|c|c|c|c|c|c|c|c|c|c|c|c|c|}
\hline \multirow[b]{2}{*}{ Unvaccinated } & \multicolumn{2}{|c|}{ <1 year $(n=3,296)$} & \multicolumn{2}{|c|}{$\begin{array}{l}1-4 \text { years } \\
(\mathrm{n}=3,549)\end{array}$} & \multicolumn{2}{|c|}{$\begin{array}{l}5-9 \text { years } \\
(\mathrm{n}=2,034\end{array}$} & \multicolumn{2}{|c|}{$\begin{array}{c}10-14 \text { years } \\
(n=2,327)\end{array}$} & \multicolumn{2}{|c|}{$\begin{array}{c}15-19 \text { years } \\
(n=1,179)\end{array}$} & \multicolumn{2}{|c|}{$\begin{array}{c}\geq 20 \text { years } \\
(n=245)\end{array}$} & \multicolumn{2}{|c|}{$\begin{array}{c}\text { Total } \\
(\mathrm{n}=12,630)\end{array}$} \\
\hline & 3,274 & $99.3 \%$ & 1,357 & $38.2 \%$ & 223 & $11.0 \%$ & 188 & $8.1 \%$ & 120 & $10.2 \%$ & 63 & $25.7 \%$ & 5,225 & $41.4 \%$ \\
\hline $\begin{array}{l}\text { Vaccinated } \\
\text { with single } \\
\text { dose }\end{array}$ & 19 & $0.6 \%$ & 2,085 & $58.7 \%$ & 1,660 & $81.6 \%$ & 1,773 & $76.2 \%$ & 541 & $45.9 \%$ & 89 & $36.3 \%$ & 6,167 & $48.8 \% a$ \\
\hline $\begin{array}{l}\text { Vaccinated } \\
\text { with at least } \\
\text { two doses }\end{array}$ & 3 & $0.1 \%$ & 107 & $3.0 \%$ & 151 & $7.4 \%$ & 366 & $15.7 \%$ & 518 & $43.9 \%$ & 93 & $38.0 \%$ & 1,238 & $9.8 \%$ \\
\hline
\end{tabular}

a Of the cases vaccinated with one MMR vaccine dose $(n=6,167), 11 \%(n=656)$ were vaccinated within 14 days before onset of measles.

vulnerable populations. Timely communication through these organisations alerted other countries to respond to any imported cases. In spring 2010, Bulgaria used the opportunity of the 2010 European Immunisation Week to advocate for and gain high-level political commitment to immunisation.

\section{Discussion}

Our assessment of the outbreak relied on data collected though routine surveillance based on passively reported cases. Such systems are notorious for underreporting and incompleteness of data. On the other hand, some over-estimation of cases may have occurred since half of these were not confirmed by laboratory testing or were epidemiologically linked, and patients with other rash- and fever-like illnesses may have been wrongly reported as measles cases. Furthermore, since there are no provisions for data collection by ethnicity, the investigators could only estimate the number of Roma cases based on their observations. Moreover, our analysis on vaccination status was limited to the $48 \%$ of cases with data on this variable. Despite these limitations, the data we present strongly indicate that the Roma ethnic group was particularly susceptible to measles. Measles outbreaks have also emerged in Roma communities in other European countries [2427]. As in Bulgaria, their vulnerability was brought to light when the MV was imported from abroad.

Similar to the measles outbreak in neighbouring Greece in 2005-2006 [25], sub-optimal immunisation coverage among Roma children largely contributed to this outbreak. A cross-sectional survey of coverage with routine immunisations in children born in 2006 in the region of Sofia showed that out of 324 Roma children eligible for immunisation, only $68.8 \%(n=223)$ received the first MMR vaccine dose [28].

According to a seroprevalence survey that included 1,666 individual samples collected in 2001-2004, Bulgaria was one of several European countries that had not met the WHO targets for measles susceptibility [29]. For the 2-4 and 5-9 year-old age groups, 30.4\% and $25.9 \%$ respectively, were seronegative for measles. The WHO susceptibility targets for these consecutive age groups are $<15 \%$ and $<10 \%$ [30]. A seroprevalence survey on 249 hospitalised non-measles patients aged $\leq 65$ years conducted in 2008 by NCIPD in Burgas, Bulgaria, revealed that 51 patients $(20.5 \%(95 \% \mathrm{Cl}$ 15.6-27.0\%)) were measles IgG-negative [31]. These results suggest that the population susceptibility to measles at national level is probably higher than that indicated by the reported minimum of $94.7 \%$ immunisation coverage for the first dose of routine measles vaccination for 2003-2008 [7]. In Bulgaria, immunisation coverage is estimated using the administrative method as a proportion of the number of routinely administered vaccine doses by eligible birth cohorts of the previous year. An overestimation of the coverage may have resulted if the denominator did not include all the population targeted for vaccination. Lack of registration of Roma children with a healthcare facility has, indeed, been documented [32].

The magnitude of the outbreak underlined the substantial number of susceptible children that had accumulated gradually since the last major nationwide outbreak in 1991-1992. During the health reforms of the 1990 s there were a number of challenges in ensuring access to quality child health services, including immunisation, to the Roma minority [33]. In addition, since primary vaccine failure is reported to occur in $2-5 \%$ of vaccinated children after the first measlescontaining vaccine (MCV) dose given at 12 months of age [34], the accumulation of non-responders to the first MCV dose probably also contributed to the pool of susceptible individuals. This also explains, at least in part, the relatively large proportion $(49 \%, n=6,167)$ of cases reported having received one MCV dose, since in Bulgaria, the second dose is not given until 12 years of age. Other potential contributing factors may include incorrect documentation on vaccination status and issues with the cold chain. Nonetheless, $11 \%(n=656)$ of these cases developed measles within 14 days of vaccination, which was probably administered as part of the outbreak control measures while they were in the incubation period following infection with MV.

Roma communities are often separated from the mainstream of social and economic life in segregated, often crowded, neighbourhoods; however, there is intensive contact between the different communities. 


\section{TABLE 3}

Cases with reported major measles-related complications, Bulgaria, 2009-2011 $(\mathrm{n}=8,074)$

\begin{tabular}{|l|c|}
\hline Complication & $\begin{array}{c}\text { No. of cases }(\mathrm{n}=8,074) \\
(\% \text { of total cases with } \\
\text { complications) }\end{array}$ \\
\hline Pneumonia & $4,704(58)$ \\
\hline Diarrhoea & $3,206(40)$ \\
\hline Acute encephalitis & $15(0.20)$ \\
\hline Otitis media & $21(0.30)$ \\
\hline Pneumonia and diarrhoea & $123(2)$ \\
\hline Pneumonia and encephalitis & $5(0.10)$ \\
\hline
\end{tabular}

This explains the widespread transmission across the country, and also beyond its borders. Between 2009 and 2011, MV variant D4-Hamburg appeared in several European countries. The spread of the MV was mostly, but not exclusively, associated with travelling members of the Roma ethnic group [35].

Poor maternal education was shown to be a risk factor for the development of measles-related complications [36]. However, the high proportion of hospitalised cases reflects the MoH's recommendation to hospitalise measles patients living in poor conditions. While this measure may have benefitted patients admitted to hospital, its impact in limiting the spread of disease in the Roma community is difficult to estimate. Inadvertently, it probably intensified nosocomial transmission [37]. During this outbreak, MV transmission occurred in several healthcare settings and healthcare workers emerged as a group at risk of acquiring measles. This necessitates clear recommendations to adhere to infection control measures in healthcare settings and to ensure healthcare workers are adequately protected.

The Bulgarian health authorities implemented the necessary control measures with coordination, support and directives from the $\mathrm{MoH}$. Regular communication with the WHO Regional Office for Europe and the ECDC allowed transparency, dialogue and advice to be sought. The large number of reported cases posed a major challenge to the surveillance system that relied on time-consuming manual methods of data collection and submission. With the support of the WHO Regional Office for Europe these methods of data collection were replaced by a web-based system allowing direct and timely case-based data entry by the RHIs.

The RHIs played a key role in executing control measures despite financial and human resource limitations. Supplementary immunisation activities were instigated to first target Roma in the affected regions and later the general population. Concurrently, healthcare professionals were urged to strengthen routine immunisation services. Despite these efforts, the initial control measures were arguably not implemented rapidly and widely enough to curb the outbreak. The clinicians' unfamiliarity with the disease probably contributed to the delay in detecting cases and subsequent response to the first cases. Nevertheless, resources permitting, a nationwide vaccination campaign targeting all infants aged nine months and older, children and young adults would probably have curtailed the outbreak sooner.

The outbreak in Bulgaria has served to further develop national and local programmes in collaboration with Roma organisations with the aim of integrating better the Roma community into the health system. Bulgaria was one of the first countries in the WHO European Region to launch the Guide to Tailoring Immunisation Programmes that resulted in several efforts to be undertaken, such as improving curricula and training of RHM across the country [38-40]. In addition, Bulgaria participated in a European collaborative project, Let's Talk About Protection, which aims to communicate effectively and address patients' concerns on vaccine topics [41]. This has resulted in the publication of a practical guide to vaccination adapted to the context in Bulgaria, and intended for use by healthcare workers and visual aid material in the form of handy flip charts for general practitioners and RHM [42].

The outbreak serves as another reminder to all countries of the WHO European Region of their commitment to eliminate measles [43]. To reach this goal every country needs to ensure that their immunisation programmes achieve and maintain high vaccination coverage ( $\geq 95 \%$ ) with two MCV doses, while also identifying and closing immunity gaps across all population segments.

In conclusion, a nationwide outbreak of measles in Bulgaria during 2009-2011 resulted from the accumulation of a large susceptible population despite reported high measles vaccination coverage at national level. The outbreak particularly highlighted the vulnerability of Roma communities in Bulgaria to measles. In addition to low coverage among Roma, accumulation of non-responders to the first MCV dose could have also contributed to the pool of susceptible individuals. The development and implementation of strategies to identify susceptible individuals and close immunity gaps across all segments of the population are of vital importance in relation to reach the measles elimination goal.

\section{Acknowledgements}

We thank all epidemiologists from the Bulgarian Regional Health Inspectorates of all the 28 regions of Bulgaria for providing essential epidemiological data. We extend our gratitude to Nino Khetsuriani (Centers for Disease Control and Prevention, Atlanta, Georgia, USA) for her valuable comments and suggestions, Myriam Ben Mamou (WHO Regional Office for Europe) for her assistance with providing references, and Catharina de Kat-Reynen (WHO Regional Office for Europe) for editorial suggestions and the WHO Regional Office for Europe for funding and supporting the development of the Bulgarian measles, mumps and rubella web-based system 
for data entry and analysis. We are also grateful to Ajay Goel and Henrik Bang (Statens Serum Institut, Denmark) for assisting with data management.

\section{Conflict of interest}

None declared

\section{Authors' contributions}

LM co-ordinated the measles surveillance activities in Bulgaria, collated data and with $\mathrm{MM}$, analysed data and reviewed literature. $M M$ had the primary responsibility of writing the manuscript. AM and SS performed molecular characterisation of the measles virus and produced the related graphic. NG, ZM, AK and MK provided valuable comments and suggestions at various stages in the preparation of this manuscript.

\section{References}

1. Gacheva N, Kojouharova M, Vladimirova N, Novkirishki V, Kurchativa A, Voynova V, et al. [Acute infectious diseases in Bulgaria in 2001. Analysis of the main epidemiological indicators]. Information Journal NCIPD. 2002;40(5). Bulgarian.

2. Gatcheva N, Chakov B, Kamenova P, Vladimirova N, Popova ST, Todorova $M$, et al. [Acute infectious diseases in Bulgaria in 1992. Analysis of main epidemiological indicators]. Information Journal NCIPD. 1993;5-29(5). Bulgarian.

3. Marinova L, Kojouharova M, Mihneva Z. An ongoing measles outbreak in Bulgaria, 2009. Euro Surveill. 2009;14(26):19259. Available from: http://www.eurosurveillance.org/ViewArticle. aspx?Articleld=19259PMID: 19573512

4. Marinova L, Muscat M, Mihneva Z, Kojouharova M. An update on an ongoing measles outbreak in Bulgaria, AprilNovember 2009. Euro Surveill. 2009;14(50):19442. Available from: http://www.eurosurveillance.org/ViewArticle. aspx?Articleld=19442PMID: 20070938

5. World Health Organization (WHO) Regional Office for Europe. Eliminating measles and rubella and prevention congenital rubella infection, WHO European region strategic plan 2005-2010. Copenhagen: WHO. [Accessed 10 Jan 2015] Available from: http://www.euro.who.int/_data/assets/pdf file/ooo8/79028/E87772.pdfhttp://

6. Mihailov A, Mihneva Z. [Specific immunoprophylaxis for measles in Bulgaria]. Information Journal NCIPD. 2004;36 40(6). Bulgarian.

7. Marinova L, Kojouharova M, Mihneva Z.[Measles Epidemic in Bulgaria in 2009-2010: Reasons and Lessons Learnt]. Pediatria. 2011;1:38-43. Bulgarian. Available from: http://www. spisanie-pediatria-bg.eu/index.php?option=com_content\&vie $\mathrm{w}=$ article\&id $=268$ \& Itemid $=892$

8. National Statistical Institute (NSI). Census 2011. Sofia: NSI; 2012. [Accessed 24 Aug 2012]. Available from: www.nsi.bg/ census2011/PDOCS2/Census2011final_en.pdf

9. Verbeff PE. [Measles]. In: Verbeff PE, ed. [Special epidemiology]. Sofia: Medicina \& Fiscultura, 1957:237-252. Bulgarian.

10. Ministry of Health of Bulgaria. [Ordinance $21 / 18.07 .2005$ on the procedure for registration, notification and reporting of communicable diseases]. State Gazette. 2005;62. Bulgarian. Available from: http://www.mh.government.bg/Articles. aspx ?lang=bg-BG\&pageid $=391$ \& categoryid $=314 \&$ articleid $=552$

11. Commission decision of 19 March 2002 laying down case definitions for reporting communicable diseases to the Community network under Decision No 2119/98/EC of the European Parliament and of the Council (2002/253/EC), Official Journal of the European Communities 03.04.2002. [Accessed 24 Mar 2015]. Available from: http://eur-lex.europa.eu/ legal-content/EN/TXT/?qid=1430041389559\&uri=CELEX:3200 2D0253

12. World Health Organization (WHO). Manual for the laboratory diagnosis of measles and rubella virus infection. Second edition. Geneva: WHO; 2007. [Accessed 10 Feb 2015]. Available from: http://www.who.int/ihr/elibrary/ manual_diagn_lab_mea_rub_en.pdf

13. Tischer A, Santibanez S, Siedler A, Heider A, Hengel H. Laboratory investigations are indispensable to monitor the progress of measles elimination--results of the German
Measles Sentinel 1999-2003.J Clin Virol. 2004;31(3):165-78. DOI: $10.1016 / j . j c v .2004 .05 .007$ PMID: 15465408

14. World Health Organization (WHO)., New genotype of measles virus and update on global distribution of measles genotypes. Wkly Epidemiol Rec. 2005;80(40):347-51.PMID: 16240986

15. Thompson JD, Gibson TJ, Plewniak F, Jeanmougin F, Higgins DG. The CLUSTAL $X$ windows interface: flexible strategies for multiple sequence alignment aided by quality analysis tools. Nucleic Acids Res. 1997;25(24):4876-82. DOI: 10.1093/ nar/25.24.4876 PMID: 9396791

16. Tamura K, Dudley J, Nei M, Kumar S. MEGA4: Molecular Evolutionary Genetics Analysis (MEGA) software version 4.0.Mol Biol Evol. 2007;24(8):1596-9. DOI: 10.1093/molbev/ msmo92 PMID: 17488738

17. World Health Organization (WHO)., Measles virus nomenclature update: 2012. Wkly Epidemiol Rec. 2012;87(9):73-81.PMID: 22462199

18. Measles Nucleotide Surveillance database. [Accessed $11 \mathrm{Dec}$ 2014]. Available from: www.who-measles.org

19. National statistical Institute Bulgaria. Population. 2012 [Accessed 15 Nov 2012]. Available from: http://www.nsi.bg/ publications/Bulgaria 2012.pdf

20. Mankertz A, Mulders MN, Shulga S, Kremer JR, Brown KE, Santibanez S, et al. Molecular genotyping and epidemiology of measles virus transmission in the World Health Organization European Region, 2007-2009. I Infect Dis. 2011;204(Suppl 1):S335-42. DOI: 10.1093/infdis/jir101 PMID: 21666182

21. Rota PA, Brown K, Mankertz A, Santibanez S, Shulga S, Muller $\mathrm{CP}$, et al. Global distribution of measles genotypes and measles molecular epidemiology. J Infect Dis. 2011;204(Suppl 1):S514-23. DOI: 10.1093/infdis/jir118 PMID: 21666208

22. Ministry of Health of Bulgaria. [National programme for elimination of measles and congenital rubella infection (2005 2010).] Sofia: Ministry of Health: 2005. [Bulgarian].

23. Roma Health Mediators. Successes and Challenges. Open Society Foundations. 2011. New York.

24. Kaic B, Gjenero-Margan I, Kurecic-Filipovic S, Muscat M. A measles outbreak in Croatia, 2008. Euro Surveill. 2009;14(1):19083. Available from: http://www. eurosurveillance.org/ViewArticle.aspx?Articleld=19083PMID: 19161711

25. Georgakopoulou T, Grylli C, Kalamara E, Katerelos P, Spala G, Panagiotopoulos T. Current measles outbreak in Greece.Euro Surveill. 2006;11(2):E060223.2. Available from: http://www. eurosurveillance.org/ViewArticle.aspx?Articleld=2906PMID: 16804217

26. Curtale F, Perrelli F, Mantovani J, Ciofi degli Atti M, Filia A Nicoletti L, et al. Description of two measles outbreaks in the Lazio Region, Italy (2006-2007). Importance of pockets of low vaccine coverage in sustaining the infection. BMC Infect Dis. 2010;10(1):62. DOI: 10.1186/1471-2334-10-62 PMID: 20219143

27. Rogalska J, Santibanez S, Mankertz A, Makowka A, Szenborn L, Stefanoff P. Spotlight on measles 2010: An epidemiologica overview of measles outbreaks in Poland in relation to the measles elimination goal.Euro Surveill. 2010;15(17):19549. Available from: www.eurosurveillance.org/ViewArticle. aspx?Articleld=19549PMID: 20460084

28. Parmakova K, Kojouharova M, Borisova M, Kurchatova A. [Cross-sectional survey of vaccination coverage with routine immunisations in children born in 2006 in Sofia region]. Bulgarian. Pediatria2010;3(3):23-8.

29. Andrews N, Tischer A, Siedler A, Pebody RG, Barbara C, Cotter S, et al. Towards elimination: measles susceptibility in Australia and 17 European countries. Bull World Health Organ. 2008;86(3):197-204. DOI: 10.2471/BLT.07.041129 PMID: 18368206

30. World Health Organization (WHO)., Measles. Progress towards global control and regional elimination, 1998-1999. Wkly Epidemiol Rec. 1999;74(50):429-34.PMID: 10647325

31. Unpublished data. National Centre of Infectious and Parasitic Diseases, Sofia, Bulgaria.

32. Rechel B, Blackburn CM, Spencer NJ, Rechel B. Access to health care for Roma children in Central and Eastern Europe: findings from a qualitative study in Bulgaria.Int J Equity Health. 2009;8(1):24. DOI: 10.1186/1475-9276-8-24 PMID: 19566936

33. Rechel B, Spencer N, Blackburn C, Holland R, Rechel B. Impact of health reforms on child health services in Europe: the case of Bulgaria.Eur J Public Health. 2009;19(3):326-30. DOI: 10.1093/eurpub/ckpo27 PMID: 19304729

34. Strebel PM, Papania MJ, Dayan GH, Halsey NA. Measles vaccine. In: Plotkin SA, Orenstein WA and Offit PA, editors. Vaccines. 5th ed.: St Louis, Saunders; 2008.

35. Mankertz A, Mihneva Z, Gold H, Baumgarte S, Baillot A, Helble R, et al. Spread of measles virus D4-Hamburg, Europe, 
2008-2011. Emerg Infect Dis. 2011;17(8):1396-401. DOI: 10.3201/eid1708.101994 PMID: 21801615

36. Lim TA, Marinova L, Kojouharova M, Tsolova S, Semenza JC. Measles outbreak in Bulgaria: poor maternal educational attainment as a risk factor for medical complications. Eur J Public Health. 2013;23(4):663-9. DOI: 10.1093/eurpub/cks182 PMID: 23302763

37. Komitova R, Kunchev A, Mihneva Z, Marinova L. Nosocomial transmission of measles among healthcare workers, Bulgaria, 2010.Euro Surveill. 2011;16(15):19842. Available from: http://www.eurosurveillance.org/ViewArticle. aspx?Articleld=19842PMID: 21507322

38. World Health Organization (WHO) Regional Office for Europe. The Guide to Tailoring Immunisation Programmes (TIP). Copenhagen: WHO. [Accessed 28 Jan 2015]. Available from: http://www.euro.who.int/_data/assets/ pdf_file/0003/187347/The-Guide-to-Tailoring-ImmunisationProgrammes-TIP.pdf?ua=1

39. SAGE Working Group on Vaccine Hesitancy,Butler R, MacDonald NE. Diagnosing the determinants of vaccine hesitancy in specific subgroups: The Guide to Tailoring Immunization Programmes (TIP).Vaccine. 2015;33(34):4176-9. DOI: 10.1016/j.vaccine.2015.04.038 PMID: 25896376

40. World Health Organization (WHO). Regional Office for Europe. Tailoring Immunization Programmes. Outputs of pilot implementation in Bulgaria. Copenhagen: WHO. [Accessed 2 Feb 2015]. Available from: http://www.euro.who.int/_data/ assets/pdf file/0011/262010/Tailoring-ImmunizationProgrammes-TIP-Outputs-of-pilot-implementation-in-Bulgaria. pdf?ua=1

41. European Centre for Diseases Prevention and Control (ECDC). Let's talk about protection. [Accessed 27 Jan 2014]. Available from: http://ecdc.europa.eu/en/healthtopics/immunisation/ comms-aid/Pages/protection.aspx

42. Marinova L, Parmakova K, Kojouharova M. Striving for better communication with underserved communities in Bulgaria - A step towards improving immunisation coverage. In: Problems of Infectious and Parasitic Diseases. (42), 2. Sofia, National center of infectious and parasitic diseases; 2014. p. 35-8. ISSN 0204-915. [Accessed 27 Mar 2014]. Available from: http://www. ncipd.org/UserFiles/Problems_Pages_2014-2.pdf

43. World Health Organization (WHO). Regional Committee for Europe. Sixtieth session, 2010. Renewed commitment to elimination of measles and rubella and prevention of congenital rubella syndrome by 2015 and Sustained support for polio-free status in the WHO European Region. Copenhagen: WHO. [Accessed 27 Jan 2014]. Available from: http://www.euro. who.int/_data/assets/pdf_file/0016/122236/RC60_eRes12. pdf

\section{License and copyright}

This is an open-access article distributed under the terms of the Creative Commons Attribution (CC BY 4.0) Licence. You may share and adapt the material, but must give appropriate credit to the source, provide a link to the licence, and indicate if changes were made.

This article is copyright of the authors, 2016. 